\title{
Recent Results From Epitaxial Growth on Step Free 4H-SiC Mesas
}

Philip G. Neudeck ${ }^{1}$, Andrew J. Trunek ${ }^{2}$, David J. Spry ${ }^{2}$, J. Anthony Powell ${ }^{3}$, Hui Du ${ }^{4}$, Marek Skowronski ${ }^{4}$, Nabil D. Bassim ${ }^{5}$, Michael A. Mastro ${ }^{5}$, Mark E. Twigg ${ }^{5}$, Ronald T. Holm ${ }^{5}$, Richard L. Henry ${ }^{5}$, and Charles R. Eddy, Jr. ${ }^{5}$

${ }^{1}$ Sensors and Electronics Branch, NASA Glenn Research Center, 21000 Brookpark Road, M.S. 77-1, Cleveland, OH, 44135

${ }^{2}$ OAI, NASA Glenn Research Center, 21000 Brookpark Road, M.S. 77-1, Cleveland, OH, 44135

${ }^{3}$ Sest, Inc., NASA Glenn, 21000 Brookpark Road, M.S. 77-1, Cleveland, OH, 44135

${ }^{4}$ Dept. of Materials Science and Engineering, Carnegie Mellon University, Pittsburgh, PA, 15213

${ }^{5}$ Electronics Science and Technology Div., Naval Research Laboratory, Washington, DC, 20375

\begin{abstract}
This paper updates recent progress made in growth, characterization, and understanding of high quality homoepitaxial and heteroepitaxial films grown on step-free $4 \mathrm{H}-\mathrm{SiC}$ mesas. First, we report initial achievement of step-free $4 \mathrm{H}-\mathrm{SiC}$ surfaces with carbon-face surface polarity. Next, we will describe further observations of how step-free $4 \mathrm{H}-\mathrm{SiC}$ thin lateral cantilever evolution is significantly impacted by crystal faceting behavior that imposes non-uniform film thickness on cantilever undersides. Finally, recent investigations of in-plane lattice constant mismatch strain relief mechanisms observed for heteroepitaxial growth of $3 \mathrm{C}-\mathrm{SiC}$ as well as $2 \mathrm{H}-\mathrm{AlN} / \mathrm{GaN}$ heterofilms on step-free $4 \mathrm{H}-\mathrm{SiC}$ mesas will be reviewed. In both cases, the complete elimination of atomic heterointerface steps on the mesa structure enables uniquely well-ordered misfit dislocation arrays to form near the heterointerfaces with remarkable lack of dislocations threading vertically into the heteroepilayers. In the case of $3 \mathrm{C}-\mathrm{SiC}$ heterofilms, it has been proposed that dislocation half-loops nucleate at mesa edges and glide laterally along the step-free $3 \mathrm{C} / 4 \mathrm{H}$ interfaces. In contrast, $3 \mathrm{C}-\mathrm{SiC}$ and $2 \mathrm{H}-\mathrm{AlN} / \mathrm{GaN}$ heterofilms grown on $4 \mathrm{H}-\mathrm{SiC}$ mesas with steps exhibit highly disordered interface misfit dislocation structure coupled with 100X greater density of dislocations threading through the thickness of the heteroepilayers. These results indicate that the presence of steps at the heteroepitaxial interface (i.e., on the initial heteroepitaxial nucleation surface) plays a highly important role in the defect structure, quality, and relaxation mechanisms of single-crystal heteroepitaxial films.
\end{abstract}

\section{INTRODUCTION}

The ability to produce arrays of device sized (up to $0.4 \mathrm{~mm}$ x $0.4 \mathrm{~mm}$ ) $4 \mathrm{H}-\mathrm{SiC}$ mesas with silicon-face (0001) top surfaces entirely free of atomic scale steps [1] has enabled realization of unique and improved wide bandgap epitaxial films. For example, when heteroepitaxial films of $3 \mathrm{C}-\mathrm{SiC}$ or $\mathrm{AlN} / \mathrm{GaN}$ are properly grown on top of such step-free $4 \mathrm{H}$ mesa surfaces, 100 -fold reductions in heterofilm dislocation density have been achieved compared with growth on conventional surfaces with steps [2-4]. Furthermore, $4 \mathrm{H}-\mathrm{SiC}$ thin lateral cantilevers entirely free of dislocations have also been realized [5-7]. Despite these achievements, some physical limitations and mechanisms of step-free mesa growth processes remain to be more fully understood. This paper updates recent progress made in growth, characterization, and 
understanding of high quality homoepitaxial and heteroepitaxial films grown on step-free $4 \mathrm{H}-$ $\mathrm{SiC}$ mesas.

\section{EXPERIMENTAL}

\section{Growth of Step-Free Surfaces on 4H-SiC Carbon Face}

The basic process for realizing arrays of step-free mesas patterned across the surface of commercial on-axis $4 \mathrm{H}$ - and $6 \mathrm{H}-\mathrm{SiC}$ wafers has been thoroughly described in previous publications [1,5-8]. All these previous reports of step-free $4 \mathrm{H}-$ or $6 \mathrm{H}-\mathrm{SiC}$ mesas were carried out on silicon face (0001) surfaces. However, previous works by others have observed important differences in the epitaxial behavior between the carbon-face and silicon-face surfaces of on-axis $4 \mathrm{H}-$ and $6 \mathrm{H}-\mathrm{SiC}$. In particular, differences in surface step structure, surface adatom diffusion length and terrace nucleation probability have been reported [9-13]. Given the potential sensitivity of the step-free mesa growth process to these issues, we decided to investigate whether or not it was possible to realize step-free mesa surfaces on the $(000 \overline{1})$ carbon-face $(\mathrm{C}$ face) using the same general mesa-growth approach.

Commercially available on-axis $(000 \overline{1}) 4 \mathrm{H}-\mathrm{SiC}$ substrates (polished on both sides) were patterned by the wafer vendor [14] with a series of roughly hexagonal and square mesa shapes arrayed across the carbon-face surface by dry-etching trenches to a depth of approximately 10 $\mu \mathrm{m}$. The largest square mesa dimension in the pattern was $200 \mu \mathrm{m}$. In order to positively confirm that the mesa-patterned side of the substrate was indeed carbon face, thermal oxidation was performed on a small piece sawed from the carbon-faced mesa substrate along with an on-axis silicon-face control piece. The samples were dry oxidized in a tube furnace for 1.5 hours at $1150^{\circ} \mathrm{C}$. Following this oxidation, the carbon-face sample exhibited blue color corresponding to an oxide thickness of about $1200 \AA$, while the Si-face control sample exhibited no oxide color. Thus, the previously reported large difference in oxidation rate between silicon and carbon faces was observed [15], confirming that the mesa sample employed for the mesa growth experiment was indeed carbon-face.

The $4 \mathrm{H}-\mathrm{SiC}$ C-face mesa patterned substrate was exposed to pure step-flow growth conditions in a modified, horizontal flow, cold wall, commercial chemical vapor deposition system. The experimental procedures for processing and characterization (i.e., sample preparation, in-situ hydrogen pre-growth etch, and AFM and optical characterization) were essentially identical to our previous works conducted on silicon-face mesa samples [1,5-8]. The 60-minute epitaxial growth was conducted at a temperature of $1620{ }^{\circ} \mathrm{C}$ with 200 millibarr reactor pressure with $\mathrm{C}_{3} \mathrm{H}_{8}$ flow of $0.75 \mathrm{sccm}$ and $\mathrm{SiH}_{4}$ flow of $3.9 \mathrm{sccm}$ in $8000 \mathrm{sccm}$ hydrogen carrier gas flow.

In general, the initial carbon-face results were very consistent with our previously reported silicon-face mesa-growth observations. As with our Si-face works, the step-free yield appeared primarily limited by the presence of substrate screw dislocations (SD's). Mesas threaded by screw dislocations exhibited hexagonal growth hillocks, $1.0 \mathrm{~nm}$ (i.e., 4 Si-C bilayers) height spiral growth steps (figure 1a), and no cantilevering. Mesas not threaded by screw dislocations, including those with $200 \mu \mathrm{m}$ length dimension, were confirmed by AFM to be completely free of steps (figure 1b). Therefore, despite differences in epitaxial growth surface properties between carbon face and silicon face in $4 \mathrm{H}-\mathrm{SiC}$, we have demonstrated that it is nevertheless possible to 
achieve stepflow growth with terrace nucleation sufficiently suppressed in order to realize stepfree surfaces on the carbon face of $4 \mathrm{H}-\mathrm{SiC}$. The full range of process conditions for realizing large step-free $\mathrm{C}$-face mesas remains to be investigated in future work.

Although minimal growth rate was employed in this initial experiment, the presence or absence of small thin cantilevers on $\{11 \overline{2} 0\}$ mesa sidewalls was observable via high magnification optical microscopy. As previously reported in our silicon-face mesa growth experiments, these cantilevers formed only on mesas free of substrate screw dislocations [5].

\section{Thin 4H-SiC Cantilever Growth: Impact of Faceting and Underside Growth}

Given sufficient growth time in pure step-flow growth conditions, our previous works using silicon-face substrates have shown that thin cantilevers laterally evolve from the tops of SD-free mesa sidewalls to seamlessly extend step-free $4 \mathrm{H}-\mathrm{SiC}$ mesa surfaces $[5,6,8]$. To date, defectpreferential etching has failed to reveal any dislocations (i.e., no etch pits have been observed) in these un-coalesced homoepitaxial cantilevers. The only defects (i.e., etch pits) observed on these films occurred where cantilever growth fronts extending from separate mesas (or separate arms of a complex multi-fingered mesa shape) have coalesced in a non-progressive manner. If sufficiently enlarged, such defect-free atomically flat cantilevers should enable novel sensors, electronic, and MEMS devices.

This section presents our more recent observations regarding the evolution and enlargement of $4 \mathrm{H}-\mathrm{SiC}$ homoepitaxial thin cantilevers. In particular, the impact of crystal faceting and growth occurring on the underside of the cantilever on the lateral expansion of the step-free topside of the cantilevers is presented.
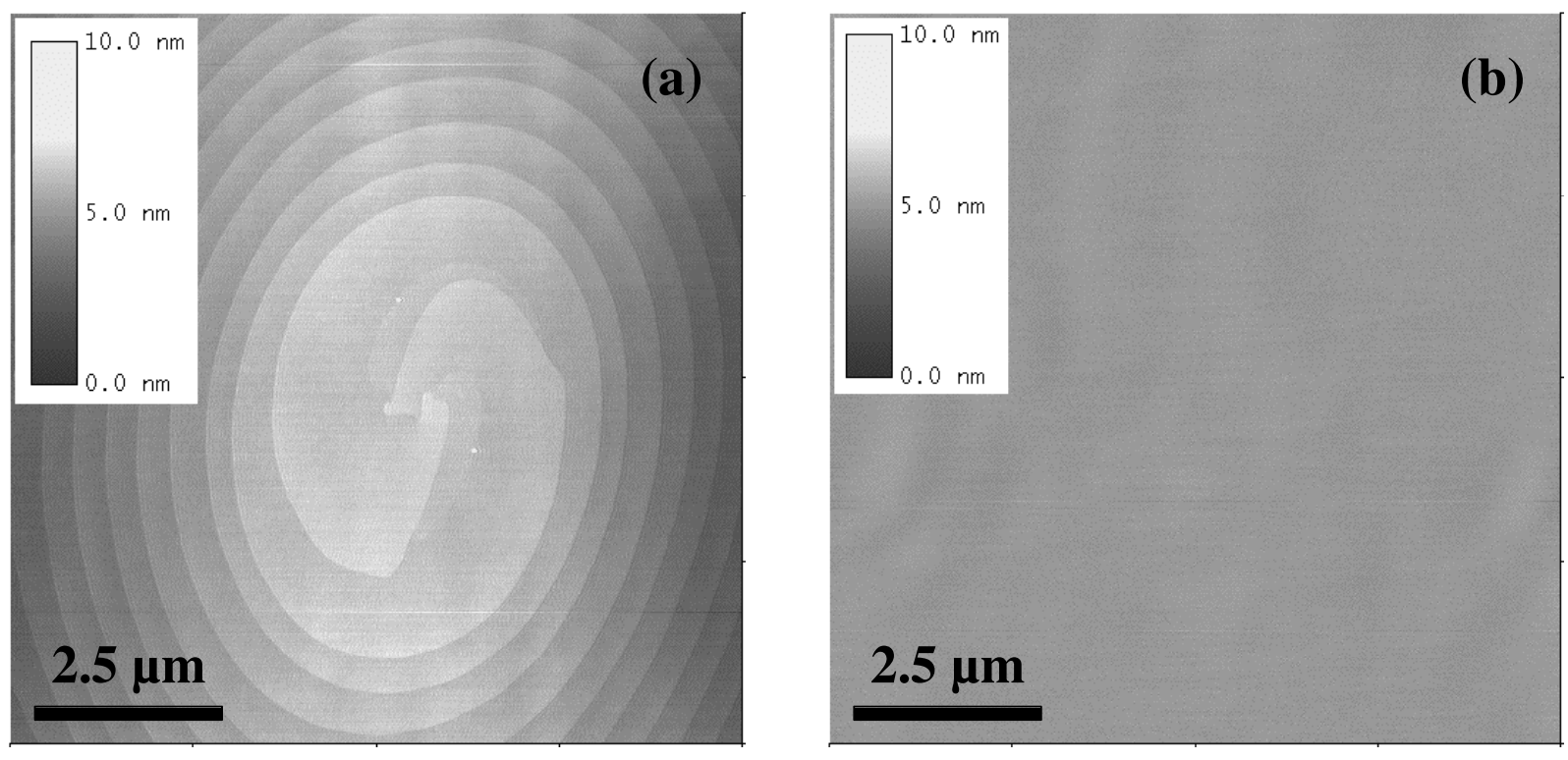

Figure 1. Atomic force microscope (AFM) scans of two nearby carbon-face 4H-SiC mesas following stepflow epitaxial growth. AFM (a) clearly shows $0.5 \mathrm{~nm}$ ( $2 \mathrm{Si}-\mathrm{C}$ bilayers) height spiral growth steps emanating from the top of a mesa threaded by an axial screw dislocation. AFM (b) shows the top surface of a nearby screw-dislocation-free mesa which is free of atomic scale steps. 
Figure 2 illustrates the significant difference in cantilever growth evolution observed for two different orientations of a simple "V" mesa shape of identical dimensions. For reference, figures $2 \mathrm{a}$ and $2 \mathrm{f}$ show optical micrographs of mesas prior to any epitaxial growth. The $\mathrm{V}$-shaped mesas, fabricated by dry etching, have arms $100 \mu \mathrm{m}$ long x $5 \mu \mathrm{m}$ wide x $20 \mu \mathrm{m}$ tall. The angle between the arms is $60^{\circ}$, so that both arms of a V-mesa have equivalent crystallographic orientation given the 6-fold in-plane symmetry of the hexagonal $\mathrm{SiC}$ crystal structure. The mesas shown on the left side of figure 2 are oriented with arms running along $<11 \overline{2} 0>$ directions, while the mesa arms shown on the right side of figure 2 run parallel to $<1 \overline{1} 00>$. Epitaxial growth on this sample was carried out for 3 hours at a pressure of 200 millibarr and a temperature of $1590^{\circ} \mathrm{C}$ with $\mathrm{C}_{3} \mathrm{H}_{8}$ flow of $1 \mathrm{sccm}, \mathrm{SiH}_{4}$ flow of $3.9 \mathrm{sccm}$, and $\mathrm{N}_{2}$ dopant flow of $10 \mathrm{sccm}$ in hydrogen carrier gas flow of $8000 \mathrm{sccm}$.

While it should have been possible to perform numerous shorter growth runs in order to document the time evolution of particular mesas, we instead took advantage of non-uniform growth rate as a function of position in our non-optimized epitaxial reactor to more quickly observe the progression of cantilever growth evolution. Therefore, all the pairs illustrated in fig. 2 resided on the same wafer and experienced the same growth time ( 3 hours), but grew at significantly different growth rates as a function of pair position across the overall quarter-wafer piece. The separation distance between the two mesas of each pair shown in figure 2 is $280 \mu \mathrm{m}$ (apex-to-apex), which is quite small compared to the $2.5 \mathrm{~cm}$ length dimension of the quarterwafer substrate. Figure $2 \mathrm{~b}$ and $2 \mathrm{~g}$ show a mesa pair where the growth rate was much smaller than for the mesa pair shown in figure $2 \mathrm{e}$ and $2 \mathrm{j}$ that experienced the highest growth rate observed across the wafer.

Even for the least-developed cantilevers (i.e., lowest growth rate) shown in figure $2 \mathrm{~b}$ and $2 \mathrm{~g}$, significant $(>2 \mathrm{X})$ lateral growth enlargement of the underlying support mesa is evident. Both the support mesa and the cantilever exhibit clear faceted growth shape behavior.

For the left mesas of figure $2 \mathrm{a}-\mathrm{e}$ where the long-arm sidewalls form stable $\{1 \overline{1} 00\}$ facets, no cantilevering takes place on the outside edges of the V-shape. In general, cantilevers are not observed on $\{1 \overline{1} 00\}$ facet sides of simple mesa shapes without concave (interior) corners. Cantilever formation is confined to the interior of the left (figure 2a-e) V-shape. The concave interior apex of the $\mathrm{V}$, with obvious kink-like geometry, apparently forms a quite favorable bonding site that promotes cantilever growth to occur near the top of the support mesa. This interior-top-corner-enhanced growth drives the leading edge of the interior cantilever beyond the stable $\{1 \overline{1} 00\}$ facet, thereby enabling further rapid enlargement of the interior cantilever (apparent in figure $2 \mathrm{~b}$-e). Therefore, mesa shapes with interior (concave) corners are necessary to drive cantilever growth fronts beyond stable $\{1 \overline{1} 00\}$ growth facets.

Mesas with arms oriented parallel to $<11 \overline{2} 0>$ (figure $2 \mathrm{f}-\mathrm{j}$ ) do form cantilevers (to at least some extent) without the presence of interior corners. However as seen in figure $2 \mathrm{~g}$ and $2 \mathrm{~h}$, $\{1 \overline{1} 00\}$ stable facets clearly evolve (in both the support mesa and the cantilevers) starting from the outermost ends of the pre-growth mesa. Once two stable facets merge to form a continuous $\{1 \overline{1} 00\}$ stable facet growth front with a convex corner, accelerated cantilever growth is effectively halted along this cantilever front. For example, the leftmost cantilever in figure $2 \mathrm{~g}$ extends in the leftward $<11 \overline{2} 0>$ direction until upper and lower $\{1 \overline{1} 00\}$ facets meet in figure $2 \mathrm{~h}$, after which there is negligible further expansion of this cantilever seen in figures $2 \mathrm{i}$ and $2 \mathrm{j}$. Even though the crystal top surface shown in figure $2 \mathrm{~h}$ is comprised completely of stable $\{1 \overline{1} 00\}$ facets, the intersection of two of these facets nevertheless meets to form a concave apex (whereas all other cantilever apex's are convex in nature). Therefore, interior-corner growth 
enhancement (described in the previous paragraph) enables further enhanced web growth of this cantilever (figure 2i) until the top surface reaches its final hexagonal shape comprised of $\{1 \overline{1} 00\}$ facets fronts intersecting at all concave apex's (figure 2j).

As the top surface of webbed $\mathrm{SiC}$ cantilever structures are atomically flat, all changes in optical contrast evident via optical microscopy are due to non-uniform film thickness on the underside of the growing cantilevers $[5,8]$. For the optical micrographs of figure 2, darker regions, such as the enlarged support mesa regions, show where the film is relatively thicker. For the final mesas shown in figures $2 \mathrm{e}$ and $2 \mathrm{j}$, darker regions (highlighted by arrows) that are not support mesas are clearly evident at $\{1 \overline{1} 00\}$ facet cantilever peripheries. In the case of the figure $2 j$ mesa, thicker (darker) regions parallel to $\{1 \overline{1} 00\}$ facets are also observed near the middle of the webbed cantilever. Though less apparent, all the thicker underside cantilever regions can also be observed in less-advanced stages of growth shown in figures $2 \mathrm{~b}-\mathrm{d}$ and $2 \mathrm{~g}-\mathrm{i}$. We surmise that the slowing of the cantilever growth front at stable $\{1 \overline{1} 00\}$ facets enables the formation of thicker underside growth. The lower reactivity of the established $\{1 \overline{1} 00\}$ cantilever sidewalls may perhaps enable mobile growth adatoms collected by the top step-free surface to better diffuse past the stable facet down to reach and bond to the near-edge regions of the cantilever undersides.

Further material analysis is required to conclusively ascertain if the regions of thicker underside $\mathrm{SiC}$ deposition are homoepitaxial $4 \mathrm{H}$ or heteroepitaxial $3 \mathrm{C}$ or some combination thereof. In order for the enhanced underside growth to be $4 \mathrm{H}-\mathrm{SiC}$, extension of underside steps inward from the existing support mesa sidewalls would
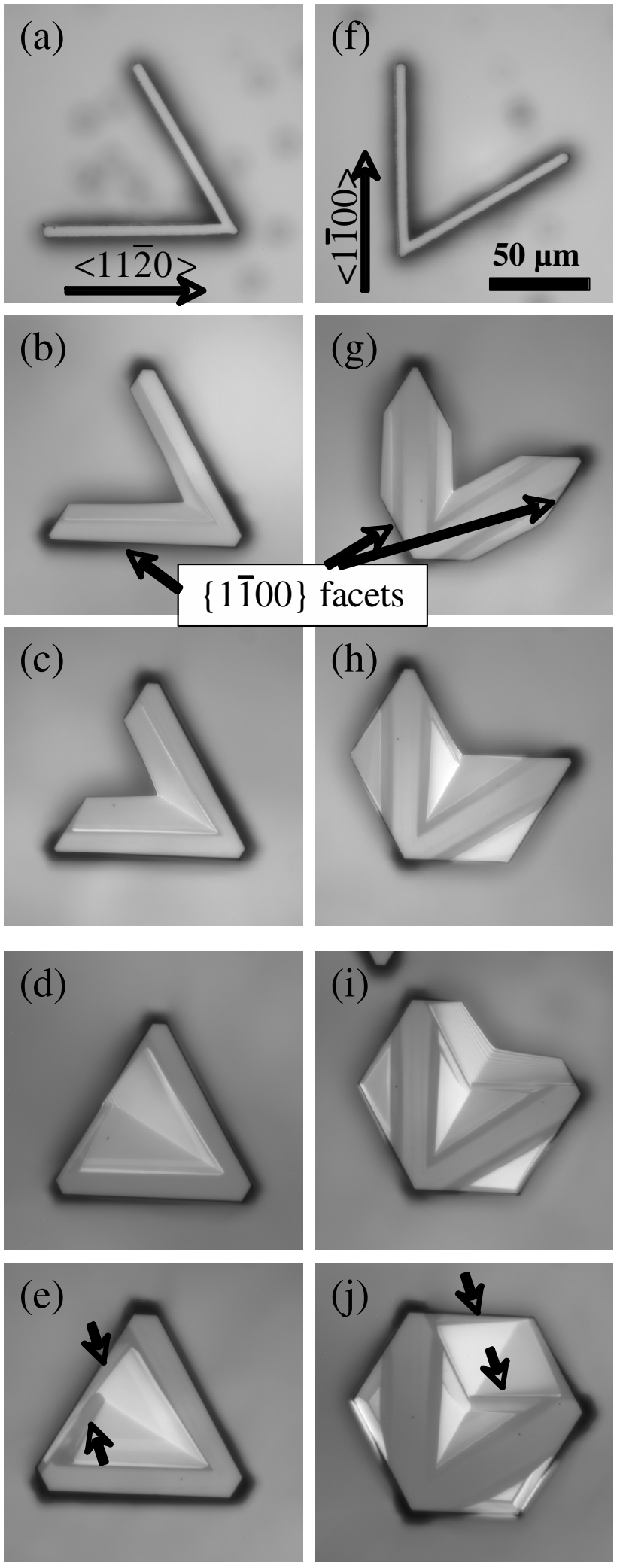

Figure 2. 4H-SiC cantilever growth evolution observed for two different orientations of a simple "V" mesa shape of identical dimensions. 
be required as the $4 \mathrm{H}$ polytype stacking template [6-9]. Such enhancement might indeed be possible, considering the concave corner-like geometry (conducive to growth enhancement) of the intersection of the vertical support mesa sidewall with the lateral cantilever underside. If the enhanced underside growth turns out to be $3 \mathrm{C}-\mathrm{SiC}$, then growth via underside terrace nucleation would be implied. The exact thickness profile of the underside growth also remains to be ascertained in future work.

Regardless of the mechanisms of non-uniform underside growth, such thickness variations could impact the micro-mechanical properties of the thin epitaxial cantilevers. Future design and optimization of devices implemented using homoepitaxial SiC cantilevers should therefore account for the possible effects of non-uniform cantilever (underside) thickness.

\section{Improved Quality AIN/GaN and 3C-SiC Mesa Heterofilms}

Recent experimental results have shown that the step-free (0001) 4H-SiC mesa growth surface uniquely enables radical improvement ( $>100$-fold reduction in dislocation density) of $2 \mathrm{H}$-AlN/GaN $[2,16,17]$ and 3C-SiC $[3,4,6,8,18,19]$ heteroepitaxial film quality. In contrast, growth of these same films on "control" $4 \mathrm{H}-\mathrm{SiC}$ "on-axis" mesas with steps yields heterofilms with abundant threading dislocations. This section reviews recent transmission electron microscopy (TEM) studies of the "step-free surface heteroepitaxy" process and its remarkably benign relaxation of substrate/heterofilm in-plane lattice mismatch. In particular, we have observed for both AlN/GaN films and 3C-SiC films grown on step-free 4H-SiC mesas, film relaxation occurs without generation of a high density of threading dislocations through the heteroepilayers. These results stand in sharp contrast to (and are quite inconsistent with) previously observed crystal heterofilm relaxation processes that are known to produce abundant threading dislocations that propagate through thicknesses of lattice-mismatched heteroepilayers.

An initial cross-sectional transmission electron microscopy (XTEM) study of 3C/4H interfacial misfit dislocation structure was conducted by our co-authors at Carnegie Mellon University (CMU) on a 15- $\mu \mathrm{m}$ thick $3 \mathrm{C}-\mathrm{SiC}$ heterofilm grown on a step-free $4 \mathrm{H}-\mathrm{SiC}$ mesa [18]. This thickness is well above the theoretically expected critical thickness of film relaxation calculated for the $3 \mathrm{C} / 4 \mathrm{H}$ system. The figure $3 \mathrm{TEM}$ shows that a well-ordered array of misfit dislocations is present near the $3 \mathrm{C} / 4 \mathrm{H} \mathrm{SiC}$ interface, with separation distance (i.e, density) within the range forecast by previous HRXRD studies (of other 3C/4H mesa samples) [19-21] and confirming that some film relaxation did indeed occur. The interfacial misfit dislocations have Burgers vector in the basal plane and are curved with mixed character. Most remarkably however, molten $\mathrm{KOH}$ etching and XTEM analysis of this mesa show that aside from misfit dislocations buried at the $3 \mathrm{C} / 4 \mathrm{H}$ interface, the $3 \mathrm{C}-\mathrm{SiC}$ film is entirely free of any dislocations [18].

Somewhat analogous behavior was observed for AlN/GaN films grown on step-free $4 \mathrm{H}-\mathrm{SiC}$ mesas [16]. Figure 4 is a series of weak-beam images taken from reflections associated with the [0001] zone axis from a low-coverage (100 $\AA$ ) AlN on a step-free $4 \mathrm{H}-\mathrm{SiC}$ mesa. These images show a series of misfit, lateral dislocations that run both parallel to the interface (observing a projection of the interface) and to each other in the unstepped mesa. Thus, similar to the $3 \mathrm{C} / 4 \mathrm{H}$ results discussed above, ordered arrays of misfit dislocations near the SiC/III-N interface are observed. In contrast, TEM images collected from low-coverage AIN grown on a stepped 4H$\mathrm{SiC}$ mesa exhibited far more dislocations with far less order $[2,16]$. 
In both the $3 \mathrm{C} / 4 \mathrm{H}$ and III-N/4H cases, the complete elimination of atomic heterointerface steps on the mesa structure apparently enables uniquely wellordered misfit dislocation arrays to form near the heterointerfaces with remarkable lack of dislocations threading through the thickness of

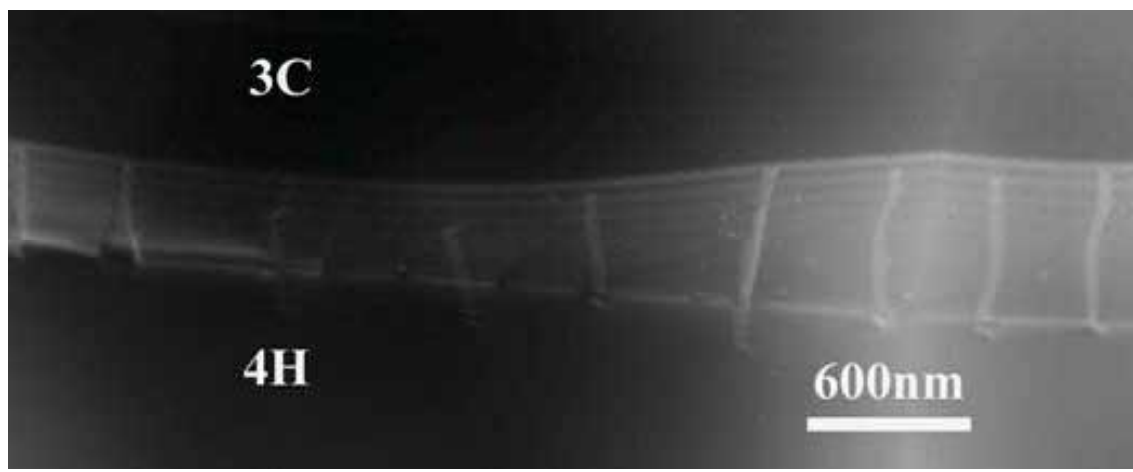

Figure 3. TEM cross-sectional bright field image of a step-free $3 \mathrm{C} / 4 \mathrm{H}$ interface [18]. Almost vertical brighter lines correspond to misfit dislocations at or near the interface. The sample was slightly tilted to reveal the dislocation lines. the heteroepilayers. The conventional model of stress relaxation in semiconductor epilayers assumes that dislocation half loops nucleate at the film top surface and glide toward the interface along inclined slip planes. Such a process is known to produce high density of threading dislocation segments in the film and misfit dislocations with Burgers vector inclined to the heterointerface. Our experimental observations of dislocations for growth on step-free $4 \mathrm{H}-\mathrm{SiC}$ mesas are not consistent with this model.

Our co-authors at CMU proposed a new relaxation mechanism (illustrated in figure 5) for the $3 \mathrm{C} / 4 \mathrm{H}$ case wherein dislocation half loops nucleate at mesa edges and then glide on planes parallel to the interface [18]. This mode of deformation is consistent with the primary slip
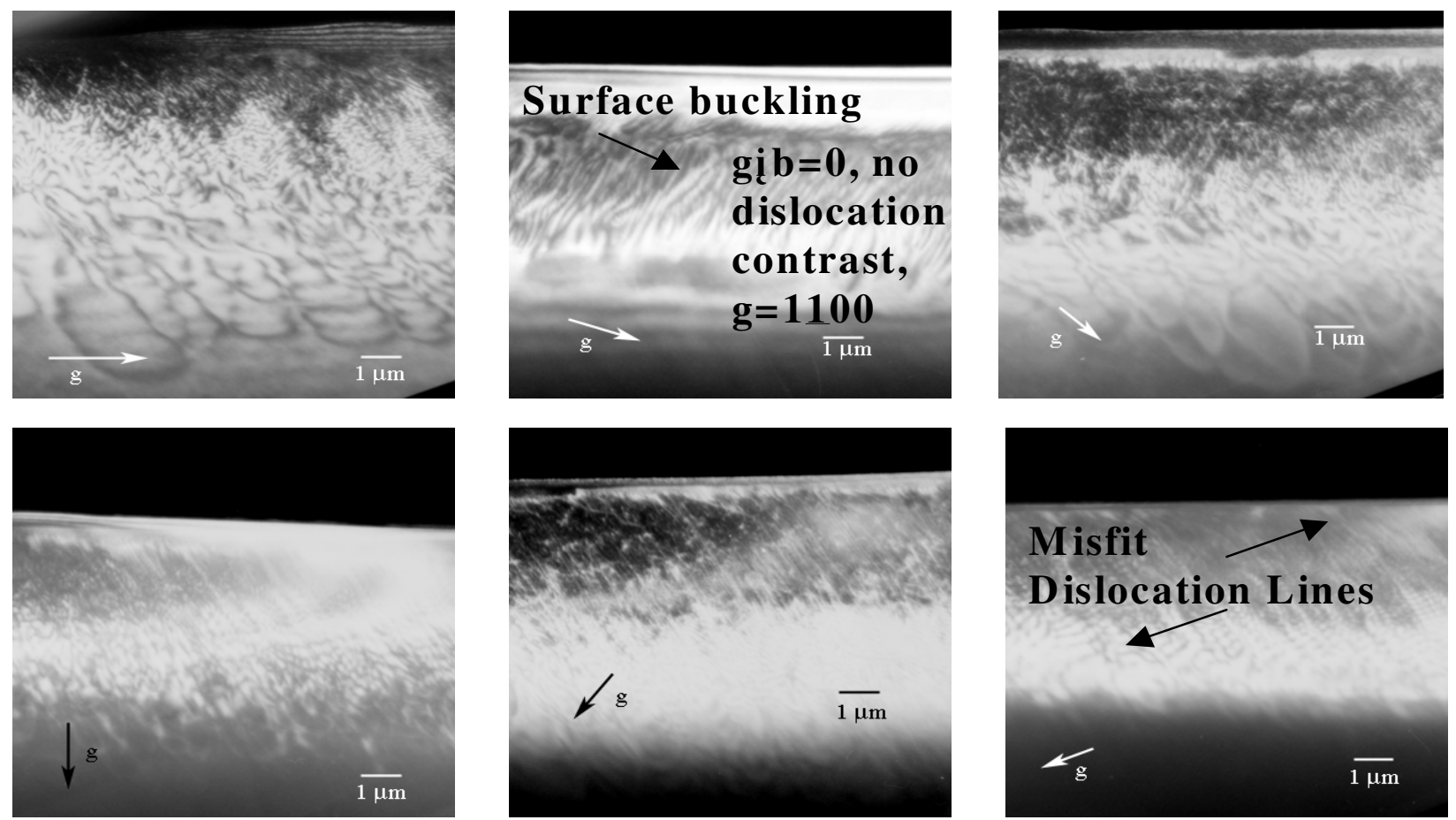

Figure 4. Weak-beam TEM imaging of thin AlN film grown on step-free 4H-SiC mesa showing that all of the interfacial misfit dislocations have the same line direction and Burgers vectors [16]. 
system $<11 \overline{2} 0>\{0001\}$ in $4 \mathrm{H} \mathrm{SiC}$ or $<110>\{111\}$ in the $3 \mathrm{C} \mathrm{SiC}$. The resolved shear stress in the basal plane of $4 \mathrm{H}$ can be produced around the mesa edges by the misfit between polytypes. Relaxation by this model does not leave threading dislocations in the film and the misfit dislocations may have mixed type with Burger's vectors in the basal plane. Therefore, the atomically flat interface appears to enable remarkably benign relaxation of lattice mismatch resulting in greatly improved heteroepitaxial film quality.

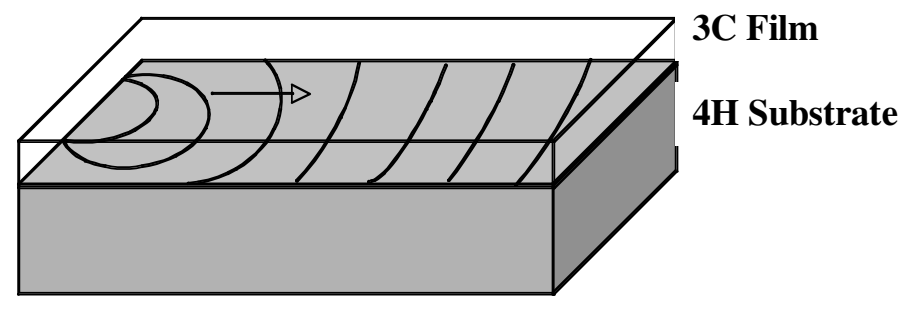

Figure 5. Proposed strain relief mechanism for a 3C$\mathrm{SiC}$ heterofilm grown on a step-free $4 \mathrm{H}-\mathrm{SiC}$ mesa [18]. Misfit dislocation half loops nucleate at mesa edges and then glide along the close-packed planes parallel to the step-free $3 \mathrm{C} / 4 \mathrm{H}$ interface. The arrow illustrates the misfit dislocation glide direction. This mode of strain relief generates no dislocations in the overlying 3C-SiC film.

\section{CONCLUSIONS}

This paper has reviewed recent progress in growth, characterization, and understanding of high quality homoepitaxial and heteroepitaxial films grown on step-free $4 \mathrm{H}-\mathrm{SiC}$ mesas. Step-free $4 \mathrm{H}-\mathrm{SiC}$ mesa surfaces with carbon-face surface polarity have been realized for the first time. The progression of $4 \mathrm{H}-\mathrm{SiC}$ thin lateral cantilever growth from mesas has been discussed in detail. In particular, the formation of $\{1 \overline{1} 00\}$ stable facets hinders the further growth extension of thin lateral cantilevers. Cantilevers expand beyond these $\{1 \overline{1} 00\}$ stable facets only when the cantilever boundary is concave. Such faceting behavior also contributes to non-uniform film growth features observed on cantilever undersides.

Essentially all previous efforts to grow heteroepitaxial films, using a wide variety of crystalline materials over the past few decades, have initiated from substrate surfaces with atomic scale steps. Our above experimental results for $3 \mathrm{C}-\mathrm{SiC}$ and III-N heterofilms grown on 4H-SiC mesa substrates indicate that atomic-scale surface steps pose a large (perhaps dominant) impediment to benign and ordered relaxation of these heteroepitaxial films. Entirely different lattice mismatch relief and greatly superior film quality result when heteroepitaxy is carried out on mesa substrate surfaces completely free of atomic scale steps. We speculate that similar results might be obtained for a wide variety of other substrate and epitaxial film materials, provided that sufficiently large step-free mesas could be implemented (via pure stepflow growth with suppressed terrace nucleation) in other substrate materials besides SiC.

The ability to grow high quality heterocrystals would clearly reap large technological benefits. This realization has driven decades of materials research towards the attainment of better crystal heteroepilayers. Some important benefits of heteroepilayers to electronics and optoelectronics have been enabled even with limited quality and combinations of materials realized to date. The ability to heteroepitaxially join far broader ranges of materials, coupled with far fewer extended crystal defects, would almost undoubtedly unlock an abundance of even more beneficial technological capability. Based upon the initial experimental studies described above, it is our contention that the step-free surface heteroepitaxy process may enable such improved 
heterocrystal layers and associated benefits to be realized. Therefore, continued study and development of the step-free surface heteroepitaxy process is clearly warranted.

\section{ACKNOWLEDGEMENTS}

Work carried out at NASA Glenn Research Center was funded and carried out under Hazardous Gas Leak Sensor, Internal Research and Development, and Ultra Efficient Engine Technology Projects. The authors wish thank B. Osborn, M. Mrdenovich, G. Beheim, G. Hunter, E. Benavage, K. Laster, C. Blaha, P. Lampard, J. Gonzalez, D. Androjna, and L. Matus at NASA Glenn for their support of this work.

\section{REFERENCES}

1. J.A. Powell, P.G. Neudeck, A.J. Trunek, G.M. Beheim, L.G. Matus, R.W. Hoffman, Jr., and L.J. Keys, Appl. Phys. Lett. 77, 1449 (2000).

2. N.D. Bassim, M.E. Twigg, C.R. Eddy, Jr., J.C. Culbertson, M.A. Mastro, R.L. Henry, R.T. Holm, P.G. Neudeck, A.J. Trunek, and J.A. Powell, Appl. Phys. Lett. 86, 021902 (2005).

3. P.G. Neudeck, J.A. Powell, D.J. Spry, A.J. Trunek, X. Huang, W.M. Vetter, M. Dudley, M. Skowronski, and J. Liu, in Silicon Carbide and Related Materials - 2002, edited by P. Bergman and E. Janzen (Materials Science Forum 433-436, Trans Tech Publications, Switzerland, 2003) p. 213.

4. P.G. Neudeck, J.A. Powell, A.J. Trunek, X.R. Huang, and M. Dudley, in Silicon Carbide and Related Materials 2001, edited by S. Yoshida et al. (Materials Science Forum 389-393, Trans Tech Publications, Switzerland, 2002) p. 311.

5. P.G. Neudeck, J.A. Powell, G.M. Beheim, E.L. Benavage, P.B. Abel, A.J. Trunek, D.J. Spry, M. Dudley, and W.M. Vetter, J. Appl. Phys. 92, 2391 (2002).

6. P.G. Neudeck, J.A. Powell, A.J. Trunek, and D.J. Spry, in Silicon Carbide and Related Materials 2003, edited by R. Madar, J. Camassel, and E. Blanquet (Materials Science Forum 457-460, Trans Tech, Switzerland, 2004) p. 169.

7. P.G. Neudeck, D.J. Spry, A.J. Trunek, J.A. Powell, and G.M. Beheim, in Silicon Carbide 2002--Materials, Processing and Devices, edited by S.E. Saddow et al. (Mat. Res. Soc. Symp. Proc. 742, Materials Research Society, Warrendale, PA, 2003) p. K5.2.1.

8. P.G. Neudeck and J.A. Powell, in Recent Major Advances in SiC, edited by W.J. Choyke, H. Matsunami, and G. Pensl (Springer-Verlag, Heidelberg, Germany, 2003, p. 179.

9. T. Kimoto, A. Itoh, and H. Matsunami, Phys. Stat. Sol. B 202, 247 (1997).

10. T. Kimoto, A. Itoh, H. Matsunami, and T. Okano, J. Appl. Phys. 81, 3494 (1997).

11. T. Kimoto and H. Matsunami, J. Appl. Phys. 75, 850 (1994).

12. T. Kimoto and H. Matsunami, J. Appl. Phys. 76, 7322 (1994).

13. T. Kimoto and H. Matsunami, J. Appl. Phys. 78, 3132 (1995).

14. Cree, Inc., http://www.cree.com.

15. Y. Song, S. Dhar, L.C. Feldman, G. Chung, and J.R. Williams, J. Appl. Phys. 95, 4953 (2004).

16. N.D. Bassim, M.E. Twigg, M.A. Mastro, P. Neudeck, C.R. Eddy, Jr., R.L. Henry, R.N. Holm, J.A. Powell, and A.J. Trunek, to appear in Silicon Carbide and Related Materials 
2005, edited by R.P. Devaty, D.J. Larkin, and S.E. Saddow (Materials Science Forum, Trans Tech Publications, Switzerland, 2006).

17. C.R. Eddy, Jr., N.D. Bassim, M.A. Mastro, R.L. Henry, M.E. Twigg, R.T. Holm, P.G. Neudeck, J.A. Powell, and A.J. Trunek, to appear in Silicon Carbide and Related Materials 2005, edited by R.P. Devaty, D.J. Larkin, and S.E. Saddow (Materials Science Forum, Trans Tech Publications, Switzerland, 2006).

18. H. Du, M. Skowronski, P.G. Neudeck, A.J. Trunek, D.J. Spry, and J.A. Powell, to appear in Silicon Carbide and Related Materials 2005, edited by R.P. Devaty, D.J. Larkin, and S.E. Saddow (Materials Science Forum, Trans Tech Publications, Switzerland, 2006).

19. X.R. Huang, M. Dudley, W. Cho, R.S. Okojie, and P.G. Neudeck, in Silicon Carbide and Related Materials 2003, edited by R. Madar, J. Camassel, and E. Blanquet (Materials Science Forum 457-460, Trans Tech, Switzerland, 2004) p. 157.

20. M. Dudley, X. Huang, and W.M. Vetter, in Silicon Carbide: Recent Major Advances, edited by W.J. Choyke, H. Matsunami, and G. Pensl (Springer-Verlag, Berlin, 2003, p. 629.

21. X. Huang, M. Dudley, P.G. Neudeck, and J.A. Powell, in Silicon Carbide 2002--Materials, Processing and Devices, edited by S.E. Saddow et al. (Mat. Res. Soc. Symp. Proc. 742, Materials Research Society, Warrendale, PA, 2003) p. K3.8.1. 